\title{
Enhanced CO tolerance of Pt clusters supported on graphene with lattice vacancies
}

\author{
Yuji Hamamoto $\odot,{ }^{1,2, *}$ Sasfan Arman Wella $\odot,{ }^{1,3}$ Kouji Inagaki $\odot,{ }^{1,2}$ Frank Abild-Pedersen $\odot,{ }^{4}$ Thomas Bligaard, ${ }^{5}$ \\ Ikutaro Hamada $\mathbb{0}^{1,2}$ and Yoshitada Morikawa ${ }^{10}{ }^{1,2,6}$ \\ ${ }^{1}$ Department of Precision Engineering, Graduate School of Engineering, Osaka University, Suita, Osaka 565-0871, Japan \\ ${ }^{2}$ Elements Strategy Initiative for Catalysts and Batteries (ESICB), Kyoto University, Goryo-Ohara, Nishikyo-ku, Kyoto 615-8245, Japan \\ ${ }^{3}$ Department of Physics, Faculty of Mathematics and Natural Sciences, Institut Teknologi Bandung, Bandung 40132, Indonesia \\ ${ }^{4}$ SUNCAT Center for Interface Science and Catalysis, SLAC National Accelerator Laboratory, 2575 Sand Hill Road, \\ Menlo Park, California 94025, USA \\ ${ }^{5}$ Catalysis Theory Center, Department of Energy Conversion and Storage, Technical University of Denmark, \\ DK-2800 Kongens Lyngby, Denmark \\ ${ }^{6}$ Research Center for Ultra-Precision Science and Technology, Graduate School of Engineering, Osaka University, \\ Suita, Osaka 565-0871, Japan
}

(Received 18 March 2020; revised 10 June 2020; accepted 24 June 2020; published 4 August 2020)

\begin{abstract}
The adsorption of $\mathrm{CO}$ on $\mathrm{Pt}_{4}$ clusters supported on graphene with lattice vacancies is studied theoretically using the first-principles calculation. Our results show that the electronic structure of the graphene-supported $\mathrm{Pt}_{4}$ clusters is significantly modified by the interaction with carbon dangling bonds. As a result the adsorption energy of $\mathrm{CO}$ at a Pt site decreases almost linearly with the lowering of the $\mathrm{Pt} d$-band center, in analogy with the linear law previously reported for $\mathrm{CO}$ adsorption on various $\mathrm{Pt}$ surfaces. An exceptional behavior is found for $\mathrm{Pt}_{4}$ supported on graphene with a tetravacancy, where $\mathrm{CO}$ adsorption is noticeably weaker than predicted by the shift in the $d$-band center. Detailed electronic structure analyses reveal that the deviation from the linear scaling can be attributed to lack of Pt $d$ states near the Fermi level that hybridize with CO molecular orbitals. The weakening of $\mathrm{CO}$ adsorption on the $\mathrm{Pt}_{4}$ clusters is considered as a manifestation of the support effect of graphene, and leads to the enhancement of $\mathrm{CO}$ poisoning tolerance that is crucial for developing high-performance Pt cluster catalysts.
\end{abstract}

DOI: 10.1103/PhysRevB.102.075408

\section{INTRODUCTION}

The extraordinary electronic and structural properties of graphene hold considerable potential for a wide variety of industrial applications. Among them, one of the most promising candidates is the application of graphene as a support material for metal nanoparticle catalysts. While platinum $(\mathrm{Pt})$ supported on carbon (C) materials has been regarded as the most practical electrocatalyst for polymer electrolyte membrane fuel cells, the position of conventional carbon support materials is now challenged by graphene, since its large specific surface area, high chemical and electrochemical stability, and high carrier mobility are well suited for a catalyst support. A great number of experiments have been carried out in the last decade (see reviews [1-11] and references therein) and it has been demonstrated that Pt supported on graphene exhibits improved catalytic activity [12], durability [13], and carbon monoxide (CO) tolerance [12] as compared with on carbon black. In particular, high-angle annular dark-field scanning transmission electron microscopy (HAADF-STEM) has revealed the existence of extraordinarily small Pt clusters on

\footnotetext{
*hamamoto@prec.eng.osaka-u.ac.jp
}

Published by the American Physical Society under the terms of the Creative Commons Attribution 4.0 International license. Further distribution of this work must maintain attribution to the author(s) and the published article's title, journal citation, and DOI. graphene, suggesting a possible contribution of these clusters to the high catalytic performance $[12,14]$. In addition, more recent HAADF-STEM measurements have even observed single Pt atoms dispersed on undoped $[15,16]$ and nitrogendoped [17] graphene, which show high catalytic activities and CO tolerance. Theoretically, on the other hand, firstprinciples calculations based on density functional theory (DFT) have been performed extensively to clarify the properties of graphene-supported Pt clusters from viewpoints of geometric [18-34] and magnetic [35-44] structures, molecular adsorptions [45-50], CO tolerance [51-54], and catalytic reactions such as CO oxidation [55-60], decomposition of $\mathrm{O}_{3}$ [61] and methanol [62], and reduction of $\mathrm{O}_{2}$ [63-65] and $\mathrm{CO}_{2}$ [66]. However, the fundamental mechanism of the support effect of graphene has yet to be clarified.

In this work, we shed light on the physical aspects of the support effect of graphene on Pt clusters, with a special emphasis on CO adsorption. We perform DFT calculations of a $\mathrm{Pt}_{4}$ cluster supported on graphene with a lattice vacancy, in which the interaction with $\mathrm{C}$ dangling bonds is expected to exert a significant impact on the electronic structure of $\mathrm{Pt}_{4}$. Our results show that the center of the $d$ band is lowered dramatically for Pt atoms near the vacancy, on which $\mathrm{CO}$ adsorption is weakened. Intriguingly, the $\mathrm{CO}$ adsorption energy decreases almost linearly with the lowering of the $d$-band center, indicating that the linear law previously reported for various $\mathrm{Pt}$ surfaces [67] is also applicable to graphene-supported Pt clusters. However, the $\mathrm{CO}$ adsorption energy on $\mathrm{Pt}_{4}$ supported on graphene with a tetravacancy turns 


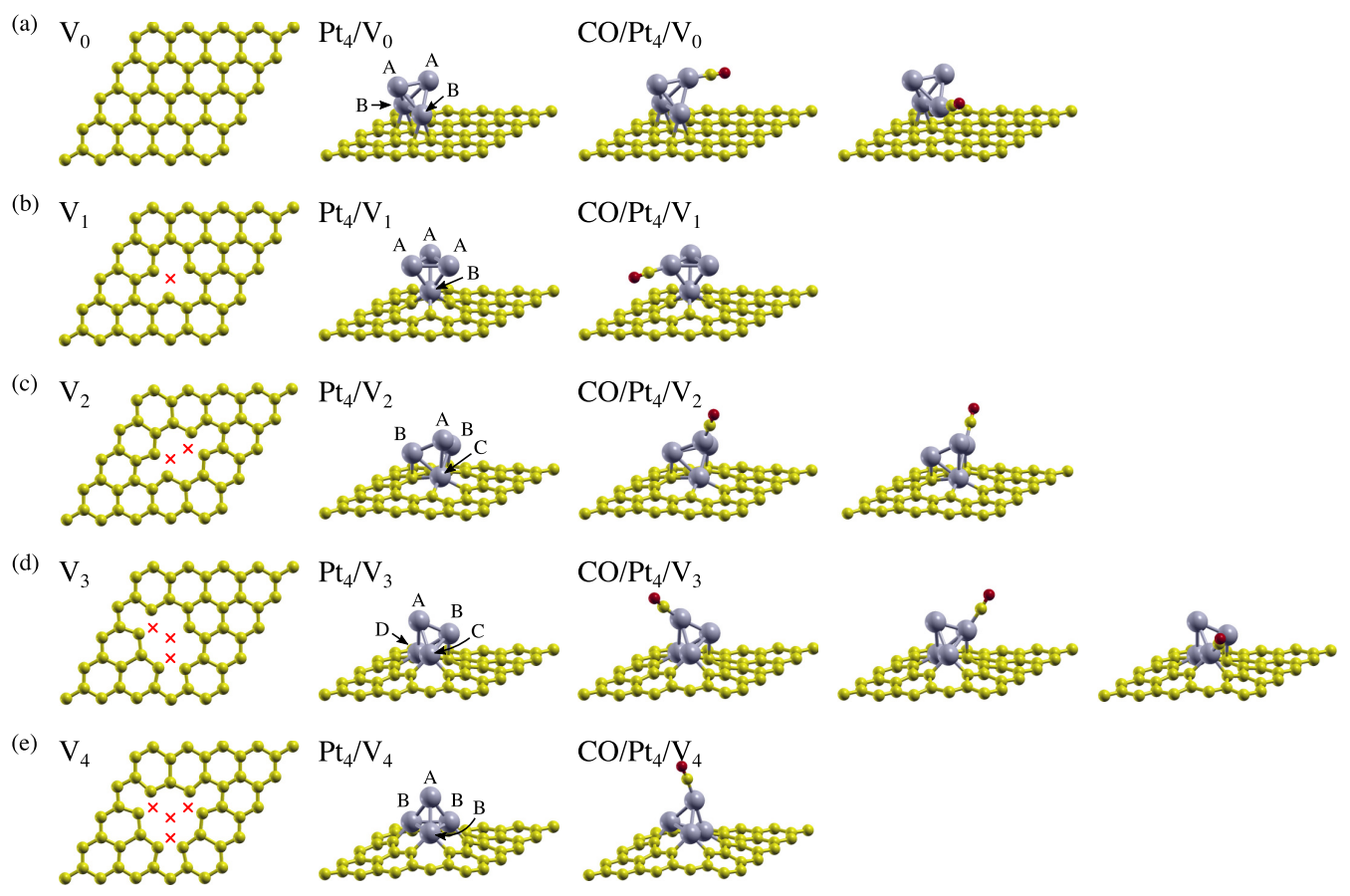

FIG. 1. Schematic views of graphene sheets without (a) and with carbon vacancies (b)-(e), and the corresponding graphene-supported $\mathrm{Pt}_{4}$ clusters and $\mathrm{CO}$ adsorption structures. In the first column, crosses $(\times)$ stand for the positions of the carbon vacancies. In the second column, inequivalent $\mathrm{Pt}$ atoms in each $\mathrm{Pt}_{4} / \mathrm{V}_{n}$ are indicated by different labels.

out to be exceptionally small relative to the corresponding $d$-band center, suggesting that the $d$-band center alone is not sufficient to describe the whole trend of $\mathrm{CO}$ adsorption on graphene-supported Pt clusters. To address the problem, we propose overlap population (OP) as a more useful descriptor, on which the $\mathrm{CO}$ adsorption energy displays a roughly linear dependence, including the system with a tetravacancy. We also derive the perturbation formula for OP, which reveals a close relation between $\mathrm{OP}$ and the $\mathrm{CO}$ adsorption energy as described below.

\section{METHODS}

The DFT calculations in the present paper are carried out using the STATE $[34,68]$ code with norm-conserving pseudopotentials [69]. The plane-wave basis set is used to expand wave functions (charge density) with cutoff energy of $64 \mathrm{Ry}$ (400 Ry). Pristine graphene is modeled with a periodically repeated $5 \times 5$ unit cell of freestanding graphene with the lattice constant of $2.46 \AA$, and $6 \times 6 \times 1 k$ points are sampled in the Brillouin zone (BZ). A lattice vacancy is formed by removing $n \mathrm{C}$ atoms with $n=1,2,3,4$ from the pristine graphene, and a supported Pt nanoparticle is modeled with a tetrahedral cluster composed of four $\mathrm{Pt}$ atoms $\left(\mathrm{Pt}_{4}\right)$. The finite-size effect in the system with $n=4$ is examined by using a $10 \times 10$ unit cell, for which $3 \times 3 \times 1 k$ points are sampled in the BZ. As a probe of the support effect, a CO molecule is adsorbed on the graphene-supported $\mathrm{Pt}_{4}$ cluster. The exchange-correlation energy and potential are described within the generalized gradient approximation using the Perdew-Burke-Ernzerhof (PBE) [70] functional, which has been widely adopted in previous calculations of Pt clusters on graphene [51,52,55-60]. The structure of each system is relaxed until the atomic forces fall below $8.24 \times 10^{-2} \mathrm{nN}$ $\left(5.14 \times 10^{-2} \mathrm{eV} / \AA\right)$. Spin polarization is taken into account for a free $\mathrm{Pt}_{4}$ cluster and graphene with an odd-numbered vacancy, while the other systems are assumed to be spin unpolarized. A vacuum layer of $30 \AA$ is introduced and the effective screening medium method [71,72] is used to eliminate the spurious electrostatic interaction with the periodic images.

\section{RESULTS AND DISCUSSION}

\section{A. $\mathbf{P t}_{\mathbf{4}}$ clusters supported on graphene with lattice vacancies}

The relaxed structures of graphene with lattice vacancies are depicted in the first column of Fig. 1, where $\mathrm{V}_{n}$ stands for graphene with $n \mathrm{C}$ vacancies with $n=0,1, \ldots, 4$. Around the lattice vacancies, the honeycomb lattice is reconstructed to saturate dangling bonds by forming nonhexagonal rings. For example, Jahn-Teller distortion breaks $D_{3 h}$ symmetry of a monovacancy in $V_{1}[73,74]$. The formation energy of $V_{n}$ is defined as

$$
E_{\text {form }}\left(\mathrm{V}_{n}\right)=E\left(\mathrm{~V}_{n}\right)-E\left(\mathrm{~V}_{0}\right)+n \mu_{\mathrm{C}},
$$

where $E\left(\mathrm{~V}_{n}\right)$ denotes the total energy of $\mathrm{V}_{n}$, and $\mu_{\mathrm{C}}$ is the $\mathrm{C}$ chemical potential defined as the total energy of pristine graphene $\mathrm{V}_{0}$ per $\mathrm{C}$ atom. The formation energies for $\mathrm{V}_{1}$, $\mathrm{V}_{2}, \mathrm{~V}_{3}$, and $\mathrm{V}_{4}$ are calculated to be $7.77,8.10,11.31$, and $12.17 \mathrm{eV}$, respectively, which compare well with previous calculations; see Refs. [75-77] and references therein. The value of $E_{\text {form }}\left(\mathrm{V}_{1}\right)$ is also in agreement with the experimental results of $>6.6 \mathrm{eV}$ estimated from vacancy concentration in quenched graphite [78] and 7.3 $\pm 1 \mathrm{eV}$ from lattice parameter change in irradiated graphite [79]. 


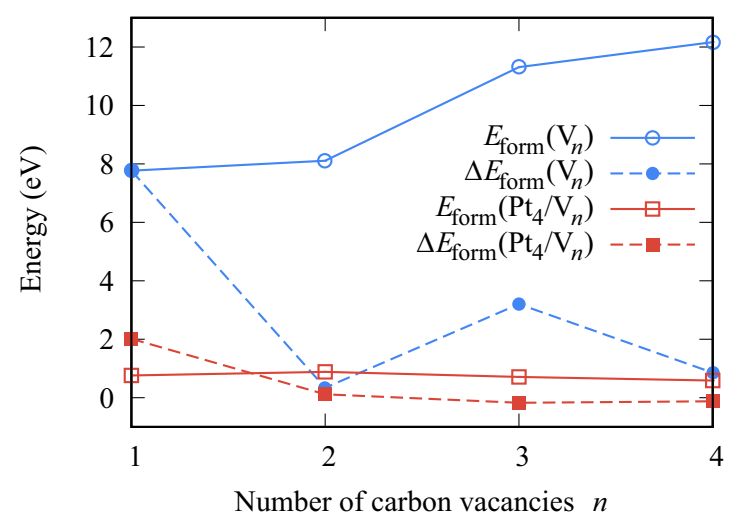

FIG. 2. Formation energies of graphene sheets with a lattice vacancy $\mathrm{V}_{n}$ (०) and graphene-supported $\mathrm{Pt}_{4}$ clusters $\mathrm{Pt}_{4} / \mathrm{V}_{n}(\square)$. Filled circles $(\bullet)$ and squares $(\boldsymbol{\square})$ correspond to the energy differences defined by Eqs. (3) and (8), respectively.

The formation energies of large vacancies can be reduced by removing $\mathrm{C}$ atoms one by one, whose energy cost is given by the difference

$$
\begin{aligned}
\Delta E_{\text {form }}\left(\mathrm{V}_{n}\right) & =E_{\text {form }}\left(\mathrm{V}_{n}\right)-E_{\text {form }}\left(\mathrm{V}_{n-1}\right) \\
& =E\left(\mathrm{~V}_{n}\right)-E\left(\mathrm{~V}_{n-1}\right)+\mu_{\mathrm{C}} .
\end{aligned}
$$

We plot $E_{\text {form }}\left(\mathrm{V}_{n}\right)$ and $\Delta E_{\text {form }}\left(\mathrm{V}_{n}\right)$ as a function of the number of $\mathrm{C}$ vacancies in Fig. 2, where odd-numbered vacancies still give larger $\Delta E_{\text {form }}\left(\mathrm{V}_{n}\right)$ than even-numbered ones. This is because the formation of an odd-numbered vacancy is accompanied by at least one unsaturated dangling bond [75], which results in spin polarization of odd-numbered vacancies [80].

We next consider adsorption of a $\mathrm{Pt}_{4}$ cluster on top of each vacancy and calculate the adsorption energy

$$
E_{\text {ads }}\left(\mathrm{Pt}_{4} / \mathrm{V}_{n}\right)=E\left(\mathrm{Pt}_{4} / \mathrm{V}_{n}\right)-E\left(\mathrm{Pt}_{4}\right)-E\left(\mathrm{~V}_{n}\right),
$$

where $E\left(\mathrm{Pt}_{4} / \mathrm{V}_{n}\right)$ and $E\left(\mathrm{Pt}_{4}\right)$ denote the total energies of the adsorbed system $\mathrm{Pt}_{4} / \mathrm{V}_{n}$ and a free $\mathrm{Pt}_{4}$ cluster, respectively. By comparing the adsorption energies for several structures, we determine the most stable adsorption structure of $\mathrm{Pt}_{4}$ on each vacancy as shown in the second column of Fig. 1. On pristine graphene, a three-legged adsorption structure is in fact slightly more stable than the two-legged one shown in Fig. 1(a), with $E_{\text {ads }}\left(\mathrm{Pt}_{4} / \mathrm{V}_{0}\right)=-1.27$ and $-1.25 \mathrm{eV}$, respectively. However, the former is destabilized upon adsorption of a $\mathrm{CO}$ molecule, and thus we here adopt the latter as the adsorption structure for $\mathrm{Pt}_{4} / \mathrm{V}_{0}$. In contrast to the weak adsorption on $\mathrm{V}_{0}, \mathrm{Pt}_{4}$ adsorbs more strongly on graphene with the vacancies; i.e., the $\mathrm{Pt}_{4}$ adsorption energies on $\mathrm{V}_{1}, \mathrm{~V}_{2}$, $\mathrm{V}_{3}$, and $\mathrm{V}_{4}$ are calculated to be $-7.00,-7.23,-10.60$, and $-11.58 \mathrm{eV}$, respectively. Note that the $\mathrm{Pt}_{4}$ adsorption energies tend to balance the large energy costs for the formation of the vacancies. Namely, if we assume that $\mathrm{V}_{n}$ is formed along with the adsorption of $\mathrm{Pt}_{4}$, the formation energy of $\mathrm{Pt}_{4} / \mathrm{V}_{n}$ defined as

$$
\begin{aligned}
E_{\text {form }}\left(\mathrm{Pt}_{4} / \mathrm{V}_{n}\right) & =E_{\text {form }}\left(\mathrm{V}_{n}\right)+E_{\text {ads }}\left(\mathrm{Pt}_{4} / \mathrm{V}_{n}\right) \\
& =E\left(\mathrm{Pt}_{4} / \mathrm{V}_{n}\right)-E\left(\mathrm{Pt}_{4}\right)-E\left(\mathrm{~V}_{0}\right)+n \mu_{\mathrm{C}}
\end{aligned}
$$

is much smaller than $E_{\text {form }}\left(\mathrm{V}_{n}\right)$ as shown in Fig. 2, although the formation of $\mathrm{Pt}_{4} / \mathrm{V}_{n}$ is still endothermic. In analogy with
Eq. (3), we also consider the difference

$$
\begin{aligned}
\Delta E_{\text {form }}\left(\mathrm{Pt}_{4} / \mathrm{V}_{n}\right) & =E_{\text {form }}\left(\mathrm{Pt}_{4} / \mathrm{V}_{n}\right)-E_{\text {form }}\left(\mathrm{Pt}_{4} / \mathrm{V}_{n-1}\right) \\
& =E\left(\mathrm{Pt}_{4} / \mathrm{V}_{n}\right)-E\left(\mathrm{Pt}_{4} / \mathrm{V}_{n-1}\right)+\mu_{\mathrm{C}},
\end{aligned}
$$

which describes the energy cost to form $\mathrm{Pt}_{4} / \mathrm{V}_{n}$ by removing a $\mathrm{C}$ atom from $\mathrm{Pt}_{4} / \mathrm{V}_{n-1}$. Although it costs large energy of $2 \mathrm{eV}$ to remove the first $\mathrm{C}$ atom, $\Delta E_{\text {form }}\left(\mathrm{Pt}_{4} / \mathrm{V}_{n}\right)$ becomes even negative, i.e., -0.17 and $-0.12 \mathrm{eV}$ for $n=3$ and 4, respectively, as shown in Fig. 2. This reveals that $\mathrm{Pt}_{4}$ adsorbed on graphene acts as a catalyst that facilitates the expansion of lattice vacancies, justifying our models of $\mathrm{Pt}$ clusters supported on large vacancies. This is qualitatively consistent with the results of TEM measurements, in which $\mathrm{Pt}$ atoms catalyze the dissociation of $\mathrm{C}-\mathrm{C}$ bonds at graphene edges $[81,82]$. Note that, by definition, $\Delta E_{\text {form }}\left(\mathrm{Pt}_{4} / \mathrm{V}_{1}\right)$ is larger than $E_{\text {form }}\left(\mathrm{Pt}_{4} / \mathrm{V}_{1}\right)$ by $E_{\text {ads }}\left(\mathrm{Pt}_{4} / \mathrm{V}_{0}\right)$, and thus forming $\mathrm{V}_{1}$ along with the adsorption of $\mathrm{Pt}_{4}$ is a more possible scenario for the formation of $\mathrm{Pt}_{4} / \mathrm{V}_{1}$.

\section{B. Local density of states projected onto the Pt $d$ states}

To investigate the support effect of graphene on the electronic structure of $\mathrm{Pt}_{4}$, we first examine the local density of states (LDOS) projected onto the $d$ states of each Pt atom in $\mathrm{Pt}_{4} / \mathrm{V}_{n}$. The calculated LDOS $\left(\rho_{d}\right)$ is plotted as a function of energy $\varepsilon$ measured from the Fermi level $\varepsilon_{\mathrm{F}}$ in Fig. 3, where, e.g., $\mathrm{Pt}_{\mathrm{A}} / \mathrm{V}_{n}$ in each panel stands for the $\mathrm{Pt}$ atom(s) labeled as A on $V_{n}$ in the second column of Fig 1. Special care should be taken for treating $\varepsilon_{\mathrm{F}}$, since it is ill defined for the DFT calculations of gapped systems. In Fig. 3 (and Fig. 5 seen below), we determine $\varepsilon_{\mathrm{F}}$ using the method as illustrated in Appendix A.

The LDOSs reflect the interactions between the $\mathrm{Pt} d$ states and graphene, and their trend can be captured by introducing the $d$-band center defined as

$$
\varepsilon_{d}=\frac{\int \varepsilon \rho_{d}(\varepsilon) d \varepsilon}{\int \rho_{d}(\varepsilon) d \varepsilon},
$$

where the energy integral is taken from $-15 \mathrm{eV}$ to $4 \mathrm{eV}$ with respect to $\varepsilon_{\mathrm{F}}$. The calculated $d$-band centers are indicated by the vertical lines in Fig. 3, and the detailed values are summarized in Table I. From Fig. 3(a), one can see that $\mathrm{Pt}_{\mathrm{A}} / \mathrm{V}_{0}$ and $\mathrm{Pt}_{\mathrm{B}} / \mathrm{V}_{0}$ have little difference in $\rho_{d}$, but the latter shows high peaks at slightly lower energies than the former. As a result the $d$-band centers of $\mathrm{Pt}_{\mathrm{A}} / \mathrm{V}_{0}$ and $\mathrm{Pt}_{\mathrm{B}} / \mathrm{V}_{0}$ are calculated to be -1.64 and $-2.39 \mathrm{eV}$, respectively. On the other hand, $\mathrm{Pt}_{\mathrm{A}} / \mathrm{V}_{1}$ and $\mathrm{Pt}_{\mathrm{B}} / \mathrm{V}_{1}$ exhibit significant difference in LDOS; i.e., the peak structures are retained for the former, while the $d$ band of the latter is broadened dramatically as shown in Fig. 3(b). The difference is due to the strong interaction between $\mathrm{Pt}_{\mathrm{B}}$ and three dangling bonds of the monovacancy, which is also reflected in the $d$-band centers of -1.65 and $-4.15 \mathrm{eV}$ for $\mathrm{Pt}_{\mathrm{A}} / \mathrm{V}_{1}$ and $\mathrm{Pt}_{\mathrm{B}} / \mathrm{V}_{1}$, respectively. A similar difference is found between $\mathrm{Pt}_{\mathrm{A}} / \mathrm{V}_{2}$ and $\mathrm{Pt}_{\mathrm{C}} / \mathrm{V}_{2}$, whose $d$-band centers are -1.82 and $-4.25 \mathrm{eV}$, respectively. The even deeper $d$ band center of the latter reflects the broader $d$ band due to the interaction between $\mathrm{Pt}_{\mathrm{C}}$ and four dangling bonds of the divacancy. Apparently, $\mathrm{Pt}_{\mathrm{B}} / \mathrm{V}_{2}$ also interacts with a dangling bond, but its narrower $d$ band with $\varepsilon_{d}=-2.33 \mathrm{eV}$ suggests that the $d$ states of $\mathrm{Pt}_{\mathrm{B}} / \mathrm{V}_{2}$ are rather close to those of $\mathrm{Pt}_{\mathrm{A}} / \mathrm{V}_{2}$. 
(a)

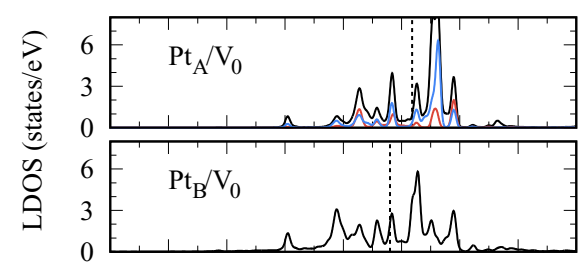

(b)

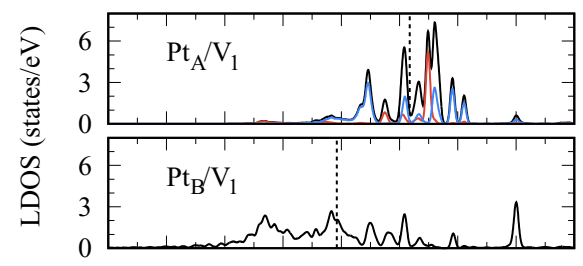

(c)

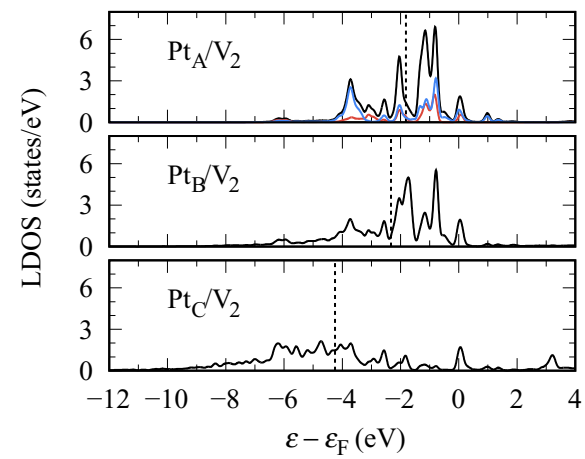

(d)

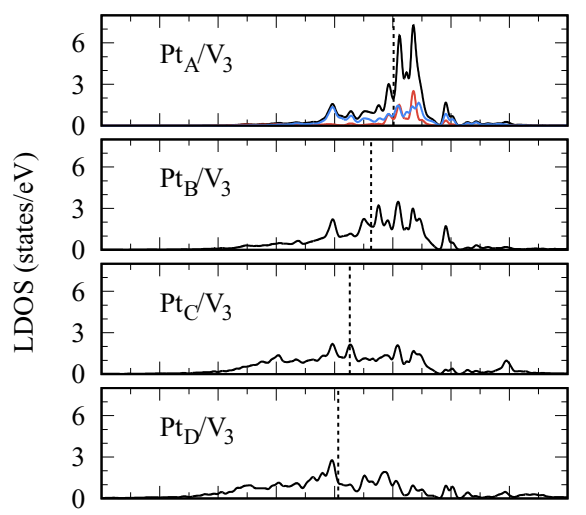

(e)

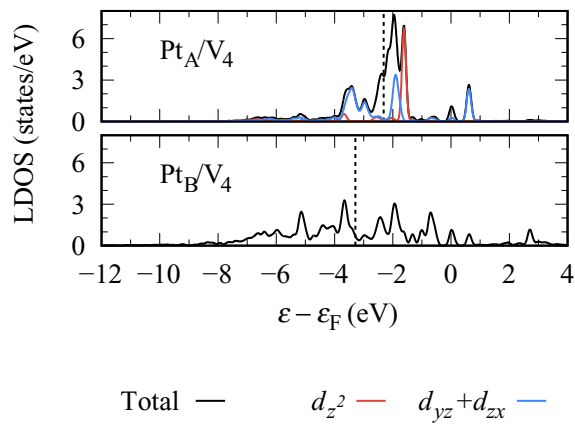

FIG. 3. LDOS projected onto the Pt $d$ states plotted as a function of energy measured from the Fermi level. The peaks are smeared by a Gaussian of width $0.1 \mathrm{eV}$. The results for $\mathrm{Pt}_{4} / \mathrm{V}_{n}$ with $n=0,1, \ldots, 4$ are shown in panels (a)-(e), respectively. In each panel, the $d$-band centers are indicated by vertical lines. The LDOSs projected onto Pt $d_{z^{2}}$ and $\left(d_{y z}+d_{z x}\right)$ states are also shown in the results for $\mathrm{Pt}_{\mathrm{A}} / \mathrm{V}_{n}$, where the $z$ axis is perpendicular to the face of $\mathrm{Pt}_{4}$ opposite to $\mathrm{Pt}_{\mathrm{A}}$.

The site dependence of the LDOS can be observed more clearly for $\mathrm{Pt}_{4} / \mathrm{V}_{3}$, since the highly asymmetric adsorption structure makes the four Pt atoms inequivalent [see Fig. 1(d)]. Namely, the $d$-band center is shifted downward monotonically as $-1.97,-2.75,-3.48$, and $-3.87 \mathrm{eV}$ for $\mathrm{Pt}_{\mathrm{A}} / \mathrm{V}_{3}, \mathrm{Pt}_{\mathrm{B}} / \mathrm{V}_{3}$, $\mathrm{Pt}_{\mathrm{C}} / \mathrm{V}_{3}$, and $\mathrm{Pt}_{\mathrm{D}} / \mathrm{V}_{3}$, respectively, as shown in Fig. 3(d). $\mathrm{Pt}_{\mathrm{C}} / \mathrm{V}_{3}$ and $\mathrm{Pt}_{\mathrm{D}} / \mathrm{V}_{3}$ are analogous to $\mathrm{Pt}_{\mathrm{B}} / \mathrm{V}_{4}$ in that they interact with two dangling bonds of a vacancy. As a result, $\varepsilon_{d}=-3.29 \mathrm{eV}$ for $\mathrm{Pt}_{\mathrm{B}} / \mathrm{V}_{4}$ is close to the $d$-band centers of $\mathrm{Pt}_{\mathrm{C}} / \mathrm{V}_{3}$ and $\mathrm{Pt}_{\mathrm{D}} / \mathrm{V}_{3}$. From the comparison among the four graphene-supported $\mathrm{Pt}_{4}$ clusters, one can also find that the $d$ band center of the topmost $\mathrm{Pt}$ atom is lowered monotonically with the size of the lattice vacancy. In particular, $\mathrm{Pt}_{\mathrm{A}} / \mathrm{V}_{4}$ exhibits a relatively deep $d$-band center of $-2.31 \mathrm{eV}$, despite the fact that the $\mathrm{Pt}$ atom has no direct bond to the tetravacancy.

\section{CO adsorption on the graphene-supported $\mathrm{Pt}_{4}$ clusters}

We next investigate the support effect of graphene on molecular adsorption. We here take $\mathrm{CO}$ as an example, which is one of the most important adsorbates relevant to fuel cell catalysts. We examine several adsorption structures of $\mathrm{CO}$ on $\mathrm{Pt}_{4} / \mathrm{V}_{n}$ and calculate the $\mathrm{CO}$ adsorption energy defined as

$E_{\mathrm{ads}}\left(\mathrm{CO} / \mathrm{Pt}_{4} / \mathrm{V}_{n}\right)=E\left(\mathrm{CO} / \mathrm{Pt}_{4} / \mathrm{V}_{n}\right)-E(\mathrm{CO})-E\left(\mathrm{Pt}_{4} / \mathrm{V}_{n}\right)$,

where $E\left(\mathrm{CO} / \mathrm{Pt}_{4} / \mathrm{V}_{n}\right)$ and $E(\mathrm{CO})$ denote the total energies of the adsorption system $\mathrm{CO} / \mathrm{Pt}_{4} / \mathrm{V}_{n}$ and a free $\mathrm{CO}$ molecule, respectively. Among a wide variety of $\mathrm{CO}$ adsorption structures, we here focus on the adsorption at on-top sites of $\mathrm{Pt}_{4} / \mathrm{V}_{n}$, since $\mathrm{CO}$ adsorbs less strongly at bridge and hollow sites of a free $\mathrm{Pt}_{4}$ cluster. The calculated adsorption energies and relevant bond lengths are summarized in Table I. Comparison of the adsorption energies reveals that $\mathrm{CO}$ prefers to adsorb at the topmost site, i.e., $\mathrm{Pt}_{\mathrm{A}}$ as depicted in the third column of Fig. 1, while CO gets destabilized as the adsorption site gets closer to graphene, and the adsorption at the bottommost Pt atoms turns out to be unstable except for $\mathrm{Pt}_{4} / \mathrm{V}_{0}$. The site dependence of the $\mathrm{CO}$ adsorption energy is closely related to the geometry of the adsorption system as shown in Figs. 4(a) and 4(b), where the adsorption energy is plotted as functions of $\mathrm{Pt}-\mathrm{C}$ and $\mathrm{C}-\mathrm{O}$ bond lengths, respectively, with $\mathrm{C}$ being the $\mathrm{C}$ atom in $\mathrm{CO}$. Figure 4(a) clearly indicates that $E_{\text {ads }}\left(\mathrm{CO} / \mathrm{Pt}_{4} / \mathrm{V}_{n}\right)$ increases monotonically as the $\mathrm{Pt}-\mathrm{C}$ bond is shortened, in agreement with the tendency that $\mathrm{CO}$ closer to $\mathrm{Pt}_{4} / \mathrm{V}_{n}$ has larger overlap between $\mathrm{CO}$ molecular orbitals (MOs) and Pt $d$ states. In contrast, Fig. 4(b) displays a monotonic increase in $E_{\mathrm{ads}}\left(\mathrm{CO} / \mathrm{Pt}_{4} / \mathrm{V}_{n}\right)$ with the elongation of the $\mathrm{C}-\mathrm{O}$ bond, suggesting that the back-donation from $\mathrm{Pt} d$ states to the antibonding $\mathrm{CO} 2 \pi$ orbital contributes to the the $\mathrm{CO}$ adsorption on $\mathrm{Pt}_{4} / \mathrm{V}_{n}$. Note, however, that the contribution of the donation from the $\mathrm{CO} 5 \sigma$ orbital to $\mathrm{Pt} d$ states cannot be inferred from Fig. 4(b), since $\mathrm{CO} 5 \sigma$ is predominantly localized at the $\mathrm{C}$ atom.

In Fig. 4(c), we also plot $E_{\text {ads }}\left(\mathrm{CO} / \mathrm{Pt}_{4} / \mathrm{V}_{n}\right)$ as a function of $\varepsilon_{d}$ in the spirit of the $d$-band model [83-85], where the nature of the $d$ states of a metal surface is represented by $\varepsilon_{d}$. Intriguingly, $E_{\mathrm{ads}}\left(\mathrm{CO} / \mathrm{Pt}_{4} / \mathrm{V}_{n}\right)$ displays an almost linear 
(a)

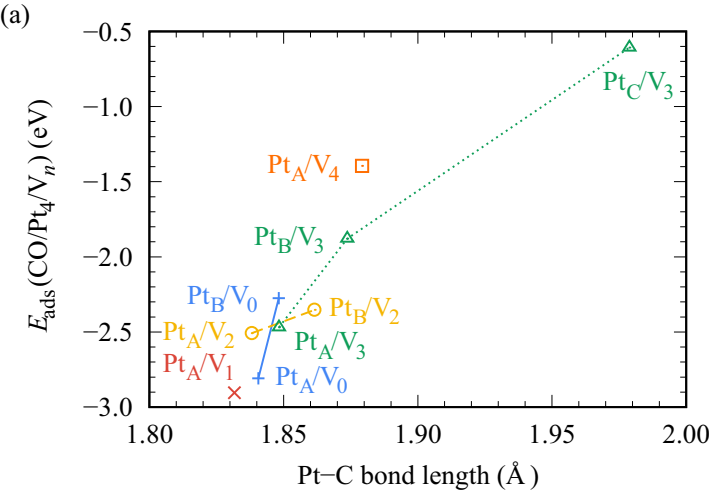

(c)

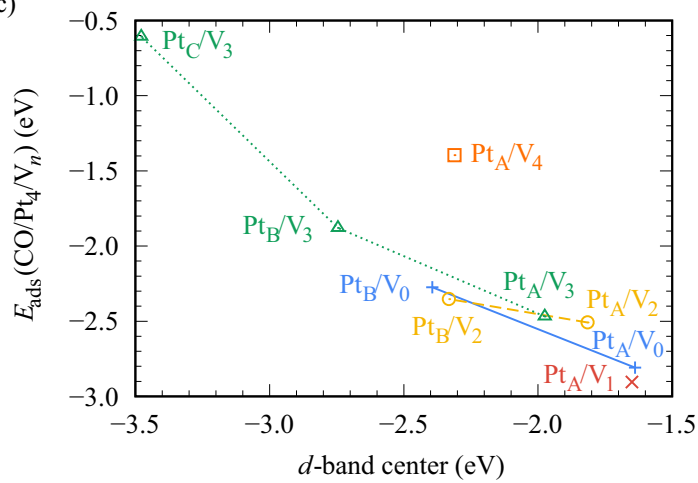

(e)

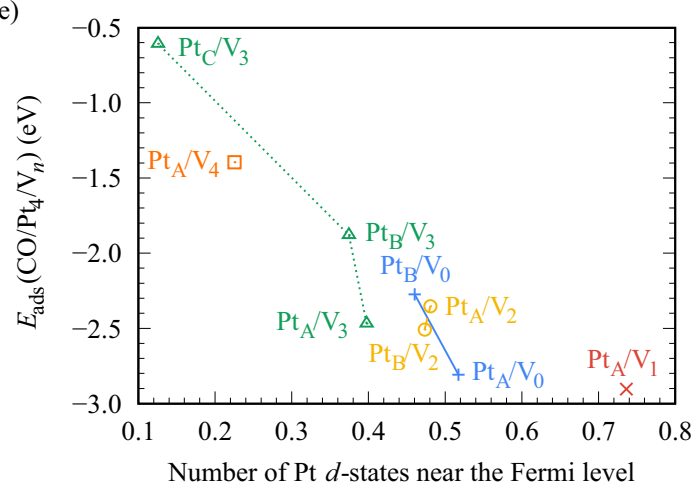

(b)

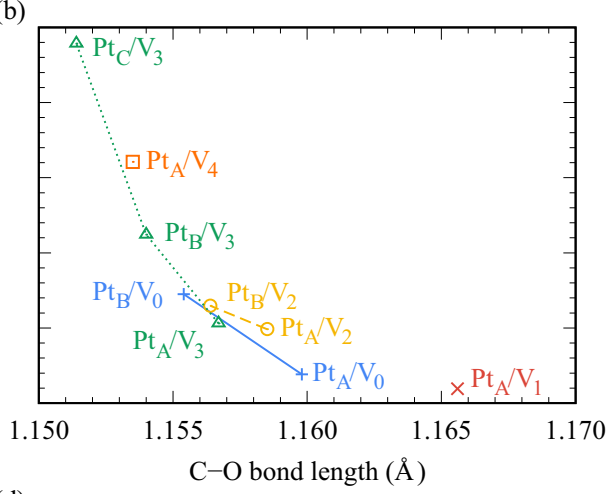

(d)

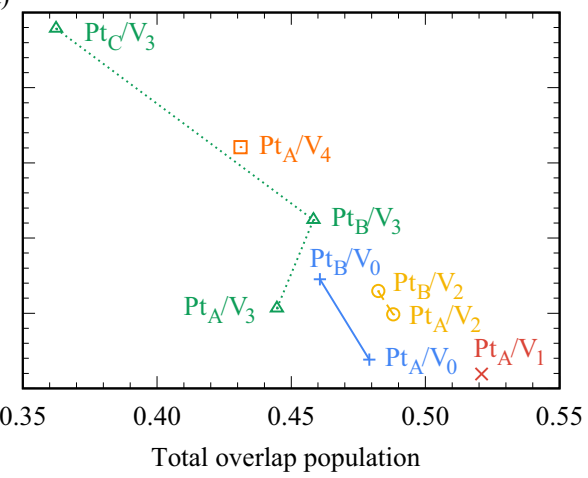

FIG. 4. CO adsorption energy plotted as a function of the Pt-C bond length (a), the $\mathrm{C}-\mathrm{O}$ bond length (b), the $d$-band center (c), the total overlap population (d), and the number of $\operatorname{Pt} d$ states near $\varepsilon_{\mathrm{F}}(\mathrm{e})$. In each panel, pluses $(+)$, crosses $(\times)$, circles $(\circ)$, triangles $(\triangle)$, and squares (ם) correspond to the results for $\mathrm{Pt}_{4} / \mathrm{V}_{n}$ with $n=0,1, \ldots, 4$, respectively. Solid, dashed, and dotted lines are drawn to guide the eye. In panel (e), the number of Pt $d$ states near $\varepsilon_{\mathrm{F}}$ is estimated by integrating the LDOS in Fig. 3 from $-0.25 \mathrm{eV}$ to $0.25 \mathrm{eV}$ with respect to $\varepsilon_{\mathrm{F}}$.

relation with $\varepsilon_{d}$, in analogy with $\mathrm{CO}$ adsorbed on various $\mathrm{Pt}$ surfaces [67]. An exception is $\mathrm{CO}$ adsorbed at $\mathrm{Pt}_{\mathrm{A}} / \mathrm{V}_{4}$, whose adsorption energy deviates significantly from the linear law. It is tempting to think that the deviation is attributed to the fact that the tetravacancy is too large relative to the unit cell or that the structure of $\mathrm{Pt}_{4} / \mathrm{V}_{4}$ is distorted significantly upon the adsorption of $\mathrm{CO}$. However, $E_{\mathrm{ads}}\left(\mathrm{CO} / \mathrm{Pt}_{4} / \mathrm{V}_{4}\right)$ remains almost unchanged even though the $10 \times 10$ unit cell is adopted, and is decreased to $-1.12 \mathrm{eV}$ if the geometry of $\mathrm{Pt}_{4} / \mathrm{V}_{4}$ is fixed during $\mathrm{CO}$ adsorption, the latter of which suggests that $\mathrm{CO}$ adsorption is in fact stabilized by the distortion of $\mathrm{Pt}_{4} / \mathrm{V}_{4}$. The deviation from the linear law indicates that the $d$-band center alone is not sufficient to explain the mechanism of $\mathrm{CO}$ adsorption on $\mathrm{Pt}_{4} / \mathrm{V}_{n}$. It should be noted that $E_{\text {ads }}\left(\mathrm{CO} / \mathrm{Pt}_{4} / \mathrm{V}_{4}\right)$ is even smaller than the $\mathrm{CO}$ adsorption energy of $-1.70 \mathrm{eV}$ at the on-top site of the $\mathrm{Pt}(111)$ surface at $1 / 9$ coverage. This is particularly important from an applicational point of view, since the tolerance for $\mathrm{CO}$ poisoning is crucial for developing high-performance metal catalysts. Our results demonstrate that the interaction with large vacancies in graphene can enhance the CO tolerance of supported Pt clusters, which has indeed been suggested experimentally as an origin of the high catalytic activity of graphene-supported Pt clusters [12,14]. Note that the graphene supports used in these experiments are expected to have lattice vacancies introduced in the preparation process of reducing graphene oxide.

\section{Overlap population analysis}

To gain more insight into the role of $\mathrm{CO}$ MOs in $\mathrm{CO}$ adsorption on $\mathrm{Pt}_{4} / \mathrm{V}_{n}$, we finally investigate the density of states weighted by OP [86-88], often referred to as crystal 
(a)

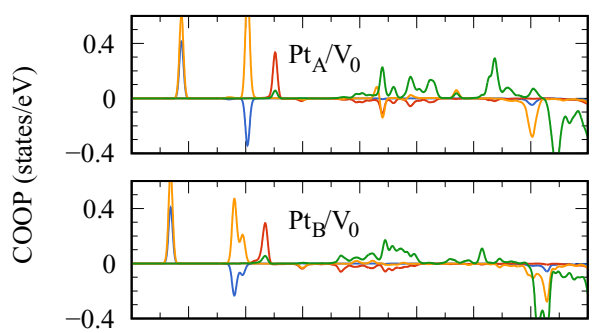

(b)

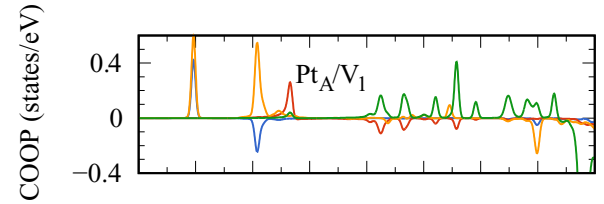

(c)

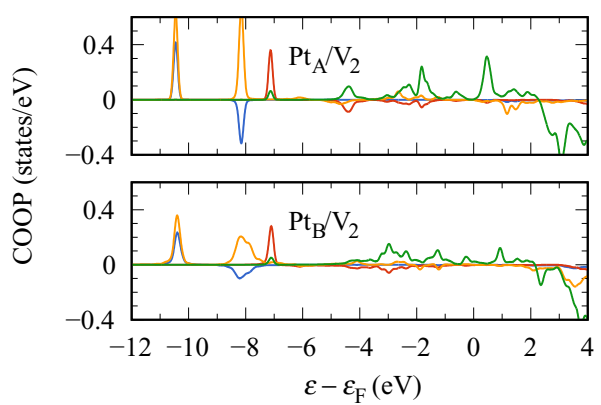

(d)

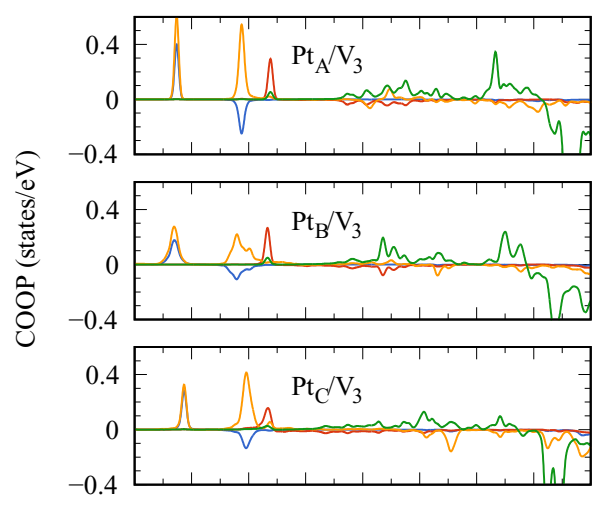

(e)

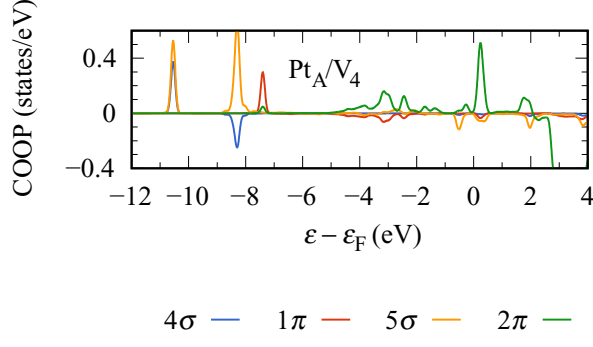

FIG. 5. COOP plotted as a function of energy measured from the Fermi level. The peaks are smeared by a Gaussian of width $0.1 \mathrm{eV}$. The results for $\mathrm{Pt}_{4} / \mathrm{V}_{n}$ with $n=0,1, \ldots, 4$ are shown in panels (a)-(e), respectively. In each panel, the COOP curves for CO $4 \sigma$ (blue), $1 \pi$ (red), $5 \sigma$ (orange), and $2 \pi$ (green) are shown.

orbital overlap population (COOP) $[89,90]$. The calculated COOP curves between CO MOs and all the states of $\mathrm{Pt}_{4} / \mathrm{V}_{n}$ are shown in Fig. 5, where positive (negative) peaks represent bonding (antibonding) states formed as a result of $\mathrm{CO}$ adsorption. The behavior of the COOP peaks can easily be understood from the perturbative expression for the OPweighted density of states, i.e., Eq. (B30) in Appendix B. Among the four CO MOs considered here, low-lying $4 \sigma$ and $1 \pi$ have both positive and negative peaks below $\varepsilon_{\mathrm{F}}$ in the COOP curves, which indicates that the bonding and antibonding contributions of these MOs almost cancel each other out. On the other hand, the existence of negative (positive) peaks derived from $5 \sigma(2 \pi)$ above (below) $\varepsilon_{\mathrm{F}}$ suggests that this $\mathrm{MO}$ contributes attractively to the $\mathrm{CO}$ adsorption through the donation (back-donation) processes. The latter behavior is consistent with the Blyholder model of $\mathrm{CO}$ adsorption on $\mathrm{Pt}$ surfaces [91].

The contributions of these MOs can be compared quantitatively by calculating OP per MO, which is obtained from the integral of COOP below $\varepsilon_{\mathrm{F}}$. The calculated results for OP are summarized in Table I, which shows that $5 \sigma$ contributes slightly more than $2 \pi$ except for $\mathrm{Pt}_{\mathrm{C}} / \mathrm{V}_{3}$, while the contributions from $4 \sigma$ and $1 \pi$ orbitals are negligibly small. More importantly, the results for $5 \sigma$ exhibit a characteristic dependence on the $\mathrm{CO}$ adsorption site. Namely, adsorption sites farther away from graphene tend to give larger OPs except for $\mathrm{Pt}_{\mathrm{A}} / \mathrm{V}_{3}$. In addition, OP for $5 \sigma$ is largest at $\mathrm{Pt}_{\mathrm{A}} / \mathrm{V}_{1}$, while it is relatively small at $\mathrm{Pt}_{\mathrm{A}} / \mathrm{V}_{4}$ as compared with other topmost $\mathrm{Pt}$ atoms. These behaviors are quite similar to the site depen- dence of $E_{\text {ads }}\left(\mathrm{CO} / \mathrm{Pt}_{4} / \mathrm{V}_{n}\right)$ discussed in the previous section. On the other hand, the relation with $E_{\text {ads }}\left(\mathrm{CO} / \mathrm{Pt}_{4} / \mathrm{V}_{n}\right)$ is less clear for $2 \pi$, unlike the dependence of $E_{\mathrm{ads}}\left(\mathrm{CO} / \mathrm{Pt}_{4} / \mathrm{V}_{n}\right)$ on the $\mathrm{C}-\mathrm{O}$ bond length shown in Fig. 4(b), where the elongation of the $\mathrm{C}-\mathrm{O}$ bond indicates the hybridization of $2 \pi$. Still, the OPs of $5 \sigma$ and $2 \pi$ tend to decrease with the size of the vacancy. In the last column of Table I, we also show the total OP for each $\mathrm{CO}$ adsorption structure, which retains the similarity to the $\mathrm{CO}$ adsorption energy. Indeed, the $\mathrm{CO}$ adsorption energy as a function of the total OP exhibits roughly linear dependence including $\mathrm{CO} / \mathrm{Pt}_{4} / \mathrm{V}_{4}$ as shown in Fig. 4(d), indicating that the $\mathrm{CO}$ adsorption energy is sensitive to the apparently small difference in the total OP.

The relation between the $\mathrm{CO}$ adsorption energy and the total OP can be understood from the fact that the hybridization between CO MOs and $\mathrm{Pt} d$ states is mainly responsible for the $\mathrm{CO}$ adsorption on $\mathrm{Pt}_{4} / \mathrm{V}_{n}$. We consider the interaction between two states $k$ and $l$ with unperturbed energies $\varepsilon_{k}$ and $\varepsilon_{l}$, respectively. To the second order in the interactions, OP between $k$ and $l$ is approximated as

$$
p_{k l}=\frac{2 \operatorname{Re}\left[S_{k l} V_{l k}\right]}{\varepsilon_{k}-\varepsilon_{l}},
$$

where $\varepsilon_{k}<\varepsilon_{\mathrm{F}}<\varepsilon_{l}$, and $S_{k l}\left(V_{l k}\right)$ denotes the overlap integral (coupling matrix element) between $k$ and $l$. See Appendix B for the derivation of Eq. (11). Specifically, $k$ and $l$ correspond to an occupied state of $\mathrm{CO}\left(\mathrm{Pt}_{4} / \mathrm{V}_{n}\right)$ and an unoccupied state of $\mathrm{Pt}_{4} / \mathrm{V}_{n}(\mathrm{CO})$, respectively, for a donation (back-donation) process. In the Mulliken-Wolfsberg-Helmholz (MWH) 
TABLE I. $d$-band center and CO adsorption energy in eV for each Pt site, lengths of Pt-C and C-O bonds in $\AA$, where $\mathrm{C}$ denotes the $\mathrm{C}$ atom bound to the $\mathrm{O}$ atom in $\mathrm{CO}$, and the overlap population between the $\mathrm{CO}$ molecular orbitals and the states of $\mathrm{Pt}_{4} / \mathrm{V}_{n}$. In the column of $\mathrm{C}-\mathrm{O}$ bond length, the value in the parentheses shows the relative difference from a free $\mathrm{CO}$ molecule, whose bond length is calculated to be $1.133 \AA$.

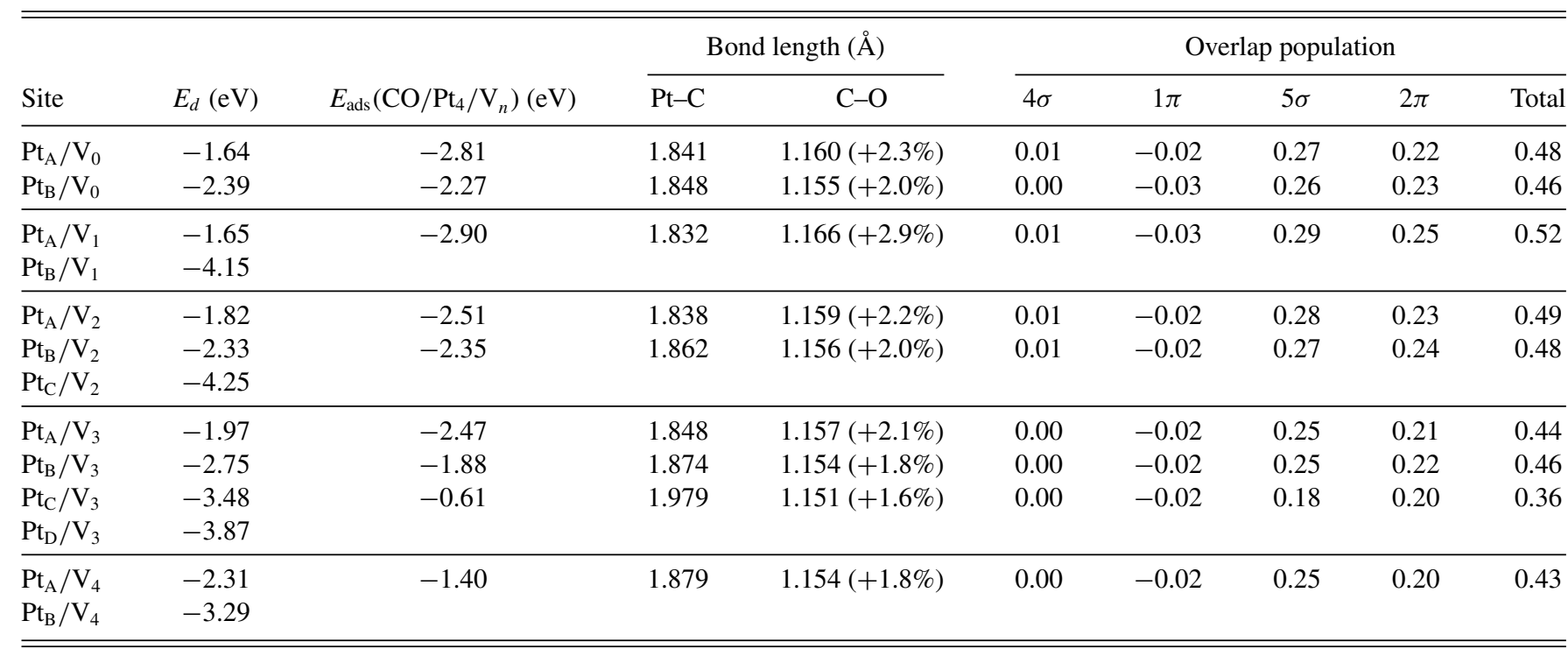

approximation $V_{l k} \simeq-\alpha S_{l k}$ with $\alpha>0 \quad[92,93], \quad p_{k l}$ is proportional to the first term of the energy correction to state $k$ given by

$$
\Delta \varepsilon_{k l}=\frac{\left|V_{k l}\right|^{2}}{\varepsilon_{k}-\varepsilon_{l}}-S_{k l} V_{l k},
$$

where the second term describes the energy cost for orthogonalization. $E_{\text {ads }}\left(\mathrm{CO} / \mathrm{Pt}_{4} / \mathrm{V}_{n}\right)$ is roughly given by the sum of $\Delta \varepsilon_{k l}$ over $k$ and $l$, which correspond to an occupied (unoccupied) orbital of $\mathrm{CO}$ and an unoccupied (occupied) state of $\mathrm{Pt}_{4} / \mathrm{V}_{n}$, respectively, in a donation (back-donation) process. Thus, $E_{\text {ads }}\left(\mathrm{CO} / \mathrm{Pt}_{4} / \mathrm{V}_{n}\right)$ is expected to scale linearly with the total OP as seen in Fig. 4(d).

To clarify the origin of the decrease in OP with the size of the vacancy, we also plot the LDOSs projected onto the $d_{z^{2}}$ and $\left(d_{y z}+d_{z x}\right)$ states of $\mathrm{Pt}_{\mathrm{A}} / \mathrm{V}_{n}$ in Fig. 3. In each system, we take the $z$ axis perpendicularly to the face of $\mathrm{Pt}_{4}$ opposite to $\mathrm{Pt}_{\mathrm{A}}$ so that $5 \sigma(2 \pi)$ has largest overlap with $d_{z^{2}}\left(d_{y z}+d_{z x}\right)$ when the $\mathrm{CO}$ axis is parallel to the $z$ direction. However, the adsorbed $\mathrm{CO}$ is in general inclined from the $z$ axis as can be seen from the third column of Fig. 1, suggesting that $d_{z^{2}}$ peaks distributed below $\varepsilon_{\mathrm{F}}$ interact repulsively with $5 \sigma$. Alternatively, the inclined adsorption structure enables $5 \sigma$ $(2 \pi)$ to overlap with $d_{y z}+d_{z x}\left(d_{z^{2}}\right)$, and thus the bond between $\mathrm{CO}$ and $\mathrm{Pt}_{\mathrm{A}} / \mathrm{V}_{n}$ consists of several interactions between $\mathrm{CO}$ MOs and $\mathrm{Pt} d$ states. In the LDOS of $\mathrm{Pt}_{\mathrm{A}} / \mathrm{V}_{0}$, for example, the peak just below $\varepsilon_{\mathrm{F}}$ is composed of $d_{z^{2}}$ and $d_{y z}+d_{z x}$, both of which hybridize with $5 \sigma$ and $2 \pi$. On the other hand, $\mathrm{Pt}_{\mathrm{A}} / \mathrm{V}_{1}$ shows two peaks derived from $d_{y z}+d_{z x}$ near $\varepsilon_{\mathrm{F}}$, while a large $d_{z^{2}}$ peak appears at $-1 \mathrm{eV}$, which indicates that the former predominantly hybridize with $5 \sigma$ and $2 \pi$. For $\mathrm{Pt}_{\mathrm{A}} / \mathrm{V}_{2}$ and $\mathrm{Pt}_{\mathrm{A}} / \mathrm{V}_{3}$, the peak near $\varepsilon_{\mathrm{F}}$, which is composed of $d_{z^{2}}$ and $d_{y z}+d_{z x}$, is smaller than those for $\mathrm{Pt}_{\mathrm{A}} / \mathrm{V}_{0}$ and $\mathrm{Pt}_{\mathrm{A}} / \mathrm{V}_{1}$, in agreement with the decreases in OP. $\mathrm{Pt}_{\mathrm{A}} / \mathrm{V}_{4}$ also shows a peak near $\varepsilon_{\mathrm{F}}$ but its $d_{y z}+d_{z x}$ component is negligibly small, while the large $d_{y z}+d_{z x}$ peaks at 0.6 and $-1.9 \mathrm{eV}$ scarcely hybridize with $5 \sigma$ and $2 \pi$, respectively. Moreover, the $d_{z^{2}}$ states at $\mathrm{Pt}_{\mathrm{A}} / \mathrm{V}_{4}$ are almost fully occupied, and the large $d_{z^{2}}$ peak at $-1.6 \mathrm{eV}$ interacts repulsively with $5 \sigma$. To confirm the importance of the $d$ states near $\varepsilon_{\mathrm{F}}$, we also plot the $\mathrm{CO}$ adsorption energy as a function of the number of $d$ states near $\varepsilon_{\mathrm{F}}\left(N_{\mathrm{F}}\right)$ as shown in Fig. $4(\mathrm{e})$, where $N_{\mathrm{F}}$ is estimated by integrating the LDOS in Fig. 3 from $-0.25 \mathrm{eV}$ to $0.25 \mathrm{eV}$ with respect to $\varepsilon_{\mathrm{F}}$. Note that the peaks in the energy range mainly consist of $d_{z^{2}}$ and/or $d_{y z}+d_{z x}$ states. Figure 4(e) shows that $E_{\text {ads }}\left(\mathrm{CO} / \mathrm{Pt}_{4} / \mathrm{V}_{n}\right)$ increases roughly linearly with $N_{\mathrm{F}}$, in analogy with the dependence on the total OP seen in Fig. 4(d). From these observations, we conclude that OP is mainly determined by the electronic structures of $\mathrm{Pt} d_{z^{2}}$ and $\left(d_{y z}+d_{z x}\right)$ states, and in particular the exceptionally small CO adsorption energy at $\mathrm{Pt}_{\mathrm{A}} / \mathrm{V}_{4}$ can be attributed to the lack of these $d$ states near $\varepsilon_{\mathrm{F}}$, as well as the repulsion between $\mathrm{Pt} d_{z^{2}}$ and $\mathrm{CO} 5 \sigma$.

\section{SUMMARY}

We have investigated theoretically $\mathrm{CO}$ adsorption on $\mathrm{Pt}_{4}$ clusters supported on graphene with lattice vacancies. The analysis of the LDOS projected onto the $\mathrm{Pt} d$ states has revealed that the $d$-band center is lowered significantly for $\mathrm{Pt}$ atoms near a vacancy, reflecting the interaction with $\mathrm{C}$ dangling bonds. As a result the adsorption energy of $\mathrm{CO}$ at a $\mathrm{Pt}$ site decreases almost linearly with the lowering of the $\mathrm{Pt} d$-band center with an exception of $\mathrm{Pt}_{4} / \mathrm{V}_{4}$, where $\mathrm{CO}$ adsorption is unusually weak relative to the corresponding $d$-band center. From a detailed analysis of OP between CO MOs and the states of $\mathrm{Pt}_{4} / \mathrm{V}_{n}$, we have also shown that the total OP tends to decrease with the size of the vacancy, and that the $\mathrm{CO}$ adsorption energy depends roughly linearly on the total OP and on the number of $d$ states near $\varepsilon_{\mathrm{F}}$, including $\mathrm{CO}$ adsorbed on $\mathrm{Pt}_{4} / \mathrm{V}_{4}$. Thus, we conclude that the exceptionally weak $\mathrm{CO}$ adsorption on $\mathrm{Pt}_{4} / \mathrm{V}_{4}$ can be attributed to the lack 
of Pt $d$ states near $\varepsilon_{\mathrm{F}}$ that have large overlap with $\mathrm{CO} 5 \sigma$ and $2 \pi$ orbitals. The approach based on OP is also applicable to other adsorption systems, in particular those in which the overlap between the electronic states of the adsorbate and the surface plays an essential role in the stability of the adsorption structure. Although further theoretical analyses are required for the elucidation of the origin of the high catalytic activity of graphene-supported Pt clusters, it is highly expected that the support effect of graphene on the Pt $d$ states not only enhances $\mathrm{CO}$ tolerance, but also has a significant impact on the catalytic activity.

\section{ACKNOWLEDGMENTS}

We thank Prof. Jens K. Nørskov, Junji Nakamura, and Takahiro Kondo for valuable discussions. S.A.W. acknowledges financial support by the Marubun Research Promotion Foundation. F.A-P. acknowledges support from the US Department of Energy, Office of Science, Office of Basic Energy Sciences, Chemical Sciences, Geosciences, and Biosciences Division, Catalysis Science Program, to the SUNCAT Center for Interface Science and Catalysis. The present study was partly supported by Grants-in-Aid for Scientific Research on Innovative Areas "3D Active-Site Science" (Grants No. JP26105010 and No. JP26105011), and "Elements Strategy Initiative for Catalysts \& Batteries" (ESICB) of the Ministry of Education, Culture, Sports, Science, and Technology, Japan (MEXT) (Grant No. JPMXP0112101003). The numerical calculations in this work have been done with the facilities of the Supercomputer Center, Institute for Solid State Physics, University of Tokyo.

\section{APPENDIX A: DETERMINATION OF THE FERMI LEVELS OF GAPPED SYSTEMS}

In Secs. III B and IIID, we have calculated the $d$-band center and overlap population, which depend on the reference from which energy levels are measured. Although the Fermi level $\varepsilon_{\mathrm{F}}$ is often used as the energy reference, it is well known that $\varepsilon_{\mathrm{F}}$ is ill defined for the DFT calculations of gapped systems. In the present systems, the formation of a vacancy or the interaction with a Pt cluster opens a finite gap in the otherwise gapless band structure of graphene. This hinders the comparison of the $d$-band center and overlap population among different systems, for which $\varepsilon_{\mathrm{F}}$ varies with the size of the energy gap. To address this problem, we have corrected the energy levels in Figs. 3 and 5 through the helium (He) $1 s$ level, as illustrated in what follows.

The first step of our approach is to determine the He $1 s$ level by considering a system composed of pristine graphene and a $\mathrm{He}$ atom in the vacuum layer. The gapless band structure of graphene remains almost unchanged as long as the He atom stays far away from graphene. This enables us to measure the He $1 s$ level from $\varepsilon_{\mathrm{F}}$, which coincides with the Dirac point of the band structure of graphene. By comparing the results for several unit cells, the He $1 s$ level is determined to be $-11.46 \mathrm{eV}$ below $\varepsilon_{\mathrm{F}}$. We next add a $\mathrm{He}$ atom to the vacuum layer of $\mathrm{Pt}_{4} / \mathrm{V}_{n}$ or $\mathrm{CO} / \mathrm{Pt}_{4} / \mathrm{V}_{n}$, in which the $\mathrm{He} 1 \mathrm{~s}$ level obtained from the DFT calculation is in general shifted from the above value, reflecting the ambiguity in $\varepsilon_{\mathrm{F}}$. Since the other energy levels are shifted parallel to the He $1 s$ level, the correct energy levels as well as $\varepsilon_{\mathrm{F}}$ are obtained by compensating the energy difference between the two He $1 s$ levels. It is expected that the correction method presented here is also applicable to other systems with a sufficient vacuum layer.

\section{APPENDIX B: PERTURBATION THEORY FOR ADSORPTION SYSTEMS}

In Sec. III D, we have shown the perturbation formulas for the overlap population (11) and the energy correction (12) based on a nonorthogonal basis. Note that perturbation formulas are usually derived by using an orthogonal basis, since it is in general possible to form an orthogonal basis for a Hermitian Hamiltonian. However, this is not the case for the discussion of, e.g., overlap population, in which the basis for the system is assumed to consist of several orthogonal bases formed separately for respective subsystems. Here we briefly summarize the perturbation theory based on such a nonorthogonal basis, and show an application to molecular adsorption on a surface.

\section{Preliminaries}

Consider a system composed of several subsystems weakly interacting with each other. The Hamiltonian of the system consists of two terms as

$$
H=H_{0}+V,
$$

where $H_{0}$ is the Hamiltonian of the respective subsystems and $V$ describe the interaction between them. We assume that orthonormal bases are obtained separately for the respective subsystems. A nonorthogonal basis $\{\varphi\}$ is formed by combining these bases, since eigenstates in different subsystems are in general not orthogonalized. Using the nonorthogonal basis, we address the eigenvalue problem

$$
H\left|\psi_{k}\right\rangle=E_{k}\left|\psi_{k}\right\rangle,
$$

where $\psi_{k}\left(E_{k}\right)$ is the $k$ th eigenstate (eigenenergy). $\psi_{k}$ is expanded in terms of the nonorthogonal basis as

$$
\left|\psi_{k}\right\rangle=\sum_{j}\left|\varphi_{j}\right\rangle c_{j k}
$$

and substituted into Eq. (B2). Multiplying both sides by $\left\langle\varphi_{i}\right|$ from the left, we have

$$
\sum_{j}\left[S_{i j}\left(\varepsilon_{j}-E_{k}\right)+V_{i j}\right] c_{j k}=0,
$$

with the $j$ th eigenenergy $\varepsilon_{j}$ of $H_{0}$, overlap integral $S_{i j} \equiv$ $\left\langle\varphi_{i} \mid \varphi_{j}\right\rangle$, and coupling matrix element $V_{i j}=\left\langle\varphi_{i}|V| \varphi_{j}\right\rangle$. Since the eigenstates in $\{\varphi\}$ are normalized but orthogonalized only in the respective subsystems, $S_{i j}=\delta_{i j}$ for $\varphi_{i}$ and $\varphi_{j}$ in the same subsystem, while $S_{i \neq j} \sim O\left(V_{i \neq j}\right)$ for those in different subsystems. The latter is justified by the MWH approximation $[92,93]$

$$
V_{i j} \propto S_{i j} \frac{V_{i i}+V_{j j}}{2} .
$$

In what follows, we treat $V$ as a perturbation and develop a perturbation theory based on the nonorthogonal basis, considering $S_{i \neq j}$ to be of the first order of smallness in $V_{i \neq j}$. 


\section{Perturbation expansion}

To solve Eq. (B4) perturbatively, eigenenergy $E_{k}$ and coefficient $c_{j k}$ are expanded as

$$
\begin{gathered}
E_{k}=E_{k}^{(0)}+E_{k}^{(1)}+\cdots, \\
c_{j k}=c_{j k}^{(0)}+c_{j k}^{(1)}+\cdots,
\end{gathered}
$$

and substituted into Eq. (B4). Here and in what follows, superscript $(n)$ stands for the $n$th order in $V$. From the zerothand first-order terms, we have

$$
\begin{gathered}
\left(\varepsilon_{i}-E_{k}^{(0)}\right) c_{i k}^{(0)}=0, \\
-\delta_{i k} E_{k}^{(1)}+V_{i k}+\left(\varepsilon_{i}-\varepsilon_{k}\right) c_{i k}^{(1)}=0,
\end{gathered}
$$

which take the same forms as those derived for an orthogonal basis. Clearly, Eq. (B8) is satisfied by setting

$$
E_{k}^{(0)}=\varepsilon_{k}, \quad c_{i k}^{(0)}=\delta_{i k} .
$$

To restrict ourselves to nondegenerate perturbation theory, we assume $\varepsilon_{i} \neq \varepsilon_{k}$ for different indices $i \neq k$ in Eq. (B9). In the adsorption system, this is satisfied if $i$ and $k$ are assigned to a state of the free adsorbate and that of the clean surface, respectively, which are in general nondegenerate. By setting $i=k$ and $i \neq k$ in Eq. (B9), we obtain the first-order corrections to the eigenenergy and the coefficient

$$
\begin{gathered}
E_{k}^{(1)}=V_{k k}, \\
c_{i k}^{(1)}=-\frac{V_{i k}}{\varepsilon_{i}-\varepsilon_{k}} \quad(i \neq k),
\end{gathered}
$$

respectively. In addition, $c_{k k}^{(1)}$ is determined from the normalization condition of $\psi_{k}$ as

$$
1=\left\langle\psi_{k} \mid \psi_{k}\right\rangle=1+2 \operatorname{Re}\left[c_{k k}^{(1)}\right]+O\left(V^{2}\right),
$$

which results in $c_{k k}^{(1)}=0$ by setting $c_{k k}$ to be real [94].

From the second-order terms in (B4), we have

$$
\begin{aligned}
& -S_{i k} V_{k k}-\delta_{i k} E_{k}^{(2)}+\sum_{j(\neq k)}\left[S_{i j}\left(\varepsilon_{j}-\varepsilon_{k}\right)+V_{i j}\right] c_{j k}^{(1)} \\
& -V_{k k} c_{i k}^{(1)}+\left(\varepsilon_{i}-\varepsilon_{k}\right) c_{i k}^{(2)}=0
\end{aligned}
$$

where overlap integrals appear explicitly. In the same way as for Eq. (B9), we obtain second-order corrections

$$
\begin{gathered}
E_{k}^{(2)}=\sum_{j(\neq k)}\left[\frac{\left|V_{k j}\right|^{2}}{\varepsilon_{k}-\varepsilon_{j}}-S_{k j} V_{j k}\right], \\
c_{i k}^{(2)}=\sum_{j(\neq k)} \frac{V_{i j} V_{j k}}{\left(\varepsilon_{i}-\varepsilon_{k}\right)\left(\varepsilon_{j}-\varepsilon_{k}\right)}-\frac{V_{i k} V_{k k}}{\left(\varepsilon_{i}-\varepsilon_{k}\right)^{2}} \\
+\frac{1}{\varepsilon_{i}-\varepsilon_{k}} \sum_{j} S_{i j} V_{j k} \quad(i \neq k), \\
c_{k k}^{(2)}=-\frac{1}{2} \sum_{j(\neq k)}\left[\frac{\left|V_{k j}\right|^{2}}{\left(\varepsilon_{k}-\varepsilon_{j}\right)^{2}}+\frac{2 \operatorname{Re}\left(S_{k j} V_{j k}\right)}{\varepsilon_{k}-\varepsilon_{j}}\right] .
\end{gathered}
$$

One can readily confirm that the conventional perturbation formulas for an orthonormal basis can be reproduced by setting $S_{i j}=\delta_{i j}$ in Eqs. (B15)-(B17).

\section{Adsorption energy}

To apply the perturbation formulas derived above to molecular adsorption, we assume that $V$ acts only between the states of the adsorbate and those of the surface, i.e., $E_{j}^{(1)}=0$ for all $j$. This means that, up to the second order in $V$, the energy correction to $\varphi_{k}$ is given by Eq. (B15), which consists of interactions between $\varphi_{k}$ and the remaining. In particular, the interaction energy with $\varphi_{l}$ is given by

$$
\Delta \varepsilon_{k l} \simeq \frac{\left|V_{k l}\right|^{2}}{\varepsilon_{k}-\varepsilon_{l}}-S_{k l} V_{l k}
$$

For simplicity, we assume that the adsorption has little influence on the occupations of the two states. If both $\varphi_{k}$ and $\varphi_{l}$ are occupied, the first term in Eq. (B18) is canceled out by the counterpart $\Delta \varepsilon_{l k}$, while the second term, which is approximated to be

$$
-S_{k l} V_{l k} \simeq \alpha\left|S_{k l}\right|^{2}
$$

with $\alpha>0$ [92,93], leads to destabilization. Conversely, a stable bonding state is realized when either of the two states is occupied; i.e., an occupied state of the adsorbate (surface) interacts with an unoccupied state of the surface (adsorbate), which can be considered as donation (back-donation) of electronic charge from the adsorbate (surface) to the surface (adsorbate). The contribution of hybridization to the adsorption energy is mainly described by the sum of Eq. (B18) over $k$ and $l$ with large $\left|V_{k l}\right|$ and $\varepsilon_{k} \lesssim \varepsilon_{\mathrm{F}} \lesssim \varepsilon_{l}$ or $\varepsilon_{l} \lesssim \varepsilon_{\mathrm{F}} \lesssim \varepsilon_{k}$.

\section{Overlap population}

We next consider the overlap of states between the adsorbate and the surface. To this end, we assume that the nonorthogonal basis set $\{\varphi\}$ is composed of two orthogonal subsets $A$ and $B$ formed separately for the free adsorbate and the clean surface, respectively, and rewrite Eq. (B3) as

$$
\left|\psi_{k}\right\rangle=\sum_{i \in A}\left|\varphi_{i}\right\rangle c_{i k}+\sum_{j \in B}\left|\varphi_{j}\right\rangle c_{j k}
$$

Since $S_{i j}=\delta_{i j}$ for $i, j \in A$ or $B$, the normalization condition for $\psi_{k}$ is given by

$1=\sum_{i \in A}\left|c_{i k}\right|^{2}+2 \sum_{i \in A} \sum_{j \in B} \operatorname{Re}\left(c_{i k}^{*} S_{i j} c_{j k}\right)+\sum_{j \in B}\left|c_{j k}\right|^{2}$,

in which $\left|c_{i k}\right|^{2}$ and $\left|c_{j k}\right|^{2}$ are the net populations related to $\psi_{k}$ of $\varphi_{i}$ of the adsorbate and $\varphi_{j}$ of the surface, respectively, while

$$
p_{i j k}=2 \operatorname{Re}\left(c_{i k}^{*} S_{i j} c_{j k}\right)
$$

is the overlap population between them [86-88]. It is convenient to introduce the density of states weighted by overlap population

$$
\rho_{i j}(\varepsilon)=\sum_{k} p_{i j k} \delta\left(\varepsilon-\varepsilon_{k}\right)
$$

which visualizes the distribution of the overlap population as a function of energy. The contributions of all the occupied states to the overlap population between $\varphi_{i}$ and $\varphi_{j}$ is obtained from a sum of $p_{i j k}$ over $k$ such that $\varepsilon_{k}<\varepsilon_{\mathrm{F}}$, or equivalently from 
an integral of $\rho_{i j}(\varepsilon)$ up to $\varepsilon_{\mathrm{F}}$, as

$$
p_{i j}=\sum_{k}^{\varepsilon_{k}<\varepsilon_{\mathrm{F}}} p_{i j k}=\int_{-\infty}^{\varepsilon_{\mathrm{F}}} \rho_{i j}(\varepsilon) d \varepsilon .
$$

Moreover, the states of the surface are usually treated collectively by defining

$$
\rho_{i}(\varepsilon)=\sum_{j \in B} \rho_{i j}(\varepsilon)=\sum_{j \in B} \sum_{k} p_{i j k} \delta\left(\varepsilon-\varepsilon_{k}\right),
$$

which is COOP discussed in Sec. III D.

To treat overlap population perturbatively, expansion

$$
p_{i j k}=p_{i j k}^{(0)}+p_{i j k}^{(1)}+p_{i j k}^{(2)}+\cdots,
$$

and the perturbation formulas derived above are substituted to Eq. (B22). The zeroth-, first-, and second-order terms read

$$
\begin{gathered}
p_{i j k}^{(0)}=p_{i j k}^{(1)}=0, \\
p_{i j k}^{(2)}=\frac{2 \operatorname{Re}\left(S_{i j} V_{j i}\right)}{\varepsilon_{i}-\varepsilon_{j}}\left(\delta_{i k}-\delta_{j k}\right) .
\end{gathered}
$$

Thus, up to the second order in $V$, we obtain approximate expressions for overlap population

$$
p_{i j k} \simeq \frac{2 \operatorname{Re}\left(S_{i j} V_{j i}\right)}{\varepsilon_{i}-\varepsilon_{j}}\left(\delta_{i k}-\delta_{j k}\right)
$$

and weighted density of states

$$
\rho_{i j}(\varepsilon) \simeq \frac{2 \operatorname{Re}\left(S_{i j} V_{j i}\right)}{\varepsilon_{i}-\varepsilon_{j}}\left[\delta\left(\varepsilon-\varepsilon_{i}\right)-\delta\left(\varepsilon-\varepsilon_{j}\right)\right],
$$

which enable a better understanding of these quantities. It is clear from Eq. (B29) that the contribution to $p_{i j}$ derives only from the situation in which either $\varphi_{i}$ or $\varphi_{j}$ is occupied, as in the case of adsorption energy (see Appendix B 3). If $\varepsilon_{i}<\varepsilon_{\mathrm{F}}<\varepsilon_{j}$, for example, the contributions of occupied states to overlap population add up to

$$
p_{i j} \simeq \frac{2 \operatorname{Re}\left[S_{i j} V_{j i}\right]}{\varepsilon_{i}-\varepsilon_{j}} .
$$

Correspondingly, Eq. (B30) indicates that $\rho_{i j}(\varepsilon)$ displays a positive (negative) peak at $\varepsilon=\varepsilon_{i}\left(\varepsilon_{j}\right)$, signaling the formation of a bonding (antibonding) state, although the peak actually observed should be shifted by $\simeq \Delta \varepsilon_{i j}\left(\Delta \varepsilon_{j i}\right)$.
[1] J. Hou, Y. Shao, M. W. Ellis, R. B. Moore, and B. Yi, Phys. Chem. Chem. Phys. 13, 15384 (2011).

[2] X. Huang, X. Qi, F. Boey, and H. Zhang, Chem. Soc. Rev. 41, 666 (2012).

[3] S. H. Hur and J.-N. Park, Asia-Pac. J. Chem. Eng. 8, 218 (2013).

[4] S. Zhang, Y. Shao, G. Yin, and Y. Lin, J. Mater. Chem. A 1, 4631 (2013).

[5] J. Nakamura and T. Kondo, Top. Catal. 56, 1560 (2013).

[6] H. Huang and X. Wang, J. Mater. Chem. A 2, 6266 (2014).

[7] X. Zhou, J. Qiao, L. Yang, and J. Zhang, Adv. Energy Mater. 4, 1301523 (2014).

[8] N. M. Julkapli and S. Bagheri, Int. J. Hydrogen Energ. 40, 948 (2015).

[9] L. T. Soo, K. S. Loh, A. B. Mohamad, W. R. W. Daud, and W. Y. Wong, Appl. Catal. A-Gen. 497, 198 (2015).

[10] D. Higgins, P. Zamani, A. Yu, and Z. Chen, Energy Environ. Sci. 9, 357 (2016).

[11] S. Kang, H. Kim, and Y.-H. Chung, Nano Convergence 5, 13 (2018).

[12] E. Yoo, T. Okata, T. Akita, M. Kohyama, J. Nakamura, and I. Honma, Nano Lett. 9, 2255 (2009).

[13] Y. Shao, S. Zhang, C. Wang, Z. Nie, J. Liu, Y. Wang, and Y. Lin, J. Power Sources 195, 4600 (2010).

[14] E. Yoo, T. Okada, T. Akita, M. Kohyama, I. Honma, and J. Nakamura, J. Power Sources 196, 110 (2011).

[15] S. Sun, G. Zhang, N. Gauquelin, N. Chen, J. Zhou, S. Yang, W. Chen, X. Meng, D. Geng, M. N. Banis, R. Li, S. Ye, S. Knights, G. A. Botton, T.-K. Sham, and X. Sun, Sci. Rep. 3, 1775 (2013).

[16] K. Yamazaki, Y. Maehara, C.-C. Lee, J. Yoshinobu, T. Ozaki, and K. Gohara, J. Phys. Chem. C 122, 27292 (2018).

[17] N. Cheng, S. Stambula, D. Wang, M. N. Banis, J. Liu, A. Riese, B. Xiao, R. Li, T.-K. Sham, L.-M. Liu, G. A. Botton, and X. Sun, Nat. Commun. 7, 13638 (2016).
[18] K.-J. Kong, Y. Choi, B.-H. Ryu, J.-O. Lee, and H. Chang, Mater. Sci. Eng. C 26, 1207 (2006).

[19] Y. Okamoto, Chem. Phys. Lett. 420, 382 (2006).

[20] D. H. Chi, N. T. Cuong, N. A. Tuan, Y.-T. Kim, H. T. Bao, T. Mitani, T. Ozaki, and H. Nagao, Chem. Phys. Lett. 432, 213 (2006).

[21] N. T. Cuong, A. Fujiwara, T. Mitani, and D. H. Chi, Comput. Mater. Sci. 44, 163 (2008).

[22] K. Okazaki-Maeda, Y. Morikawa, S. Tanaka, and M. Kohyama, Surf. Sci. 604, 144 (2010).

[23] M. Zhou, A. Zhang, Z. Dai, Y. P. Feng, and C. Zhang, J. Phys. Chem. C 114, 16541 (2010).

[24] D. Xian-Qi, T. Ya-Nan, D. Ya-Wei, L. Yan-Hui, Z. Jian-Hua, Z. Bao, and Y. Zong-Xian, Chin. Phys. B 20, 056801 (2011).

[25] Y. Tang, Z. Yang, and X. Dai, J. Chem. Phys. 135, 224704 (2011).

[26] I. Fampiou and A. Ramasubramaniam, J. Phys. Chem. C 116, 6543 (2012).

[27] T. Yumura, T. Awano, H. Kobayashi, and T. Yamabe, Molecules 17, 7941 (2012).

[28] G. Ramos-Sanchez and P. B. Balbuena, Phys. Chem. Chem. Phys. 15, 11950 (2013).

[29] T.-u. Park, Y. Tomita, and T. Nakayama, Surf. Sci. 621, 7 (2014).

[30] A. Chutia, I. Hamada, and M. Tokuyama, Surf. Sci. 628, 116 (2014).

[31] F. Ferrante, A. Prestianni, R. Cortese, R. Schimmenti, and D. Duca, J. Phys. Chem. C 120, 12022 (2016).

[32] L. G. Verga, J. Aarons, M. Sarwar, D. Thompsett, A. E. Russell, and C.-K. Skylaris, Phys. Chem. Chem. Phys. 18, 32713 (2016).

[33] R. N. Lenz Baldez, P. Piquini, A. A. Schmidt, and M. A. Kuroda, Phys. Chem. Chem. Phys. 19, 22153 (2017).

[34] S. A. Wella, Y. Hamamoto, Suprijadi, Y. Morikawa, and I. Hamada, Nanoscale Adv. 1, 1165 (2019). 
[35] A. V. Krasheninnikov, P. O. Lehtinen, A. S. Foster, P. Pyykkö, and R. M. Nieminen, Phys. Rev. Lett. 102, 126807 (2009).

[36] O. Üzengi Aktürk and M. Tomak, Phys. Rev. B 80, 085417 (2009).

[37] X.-Q. Dai, Y.-N. Tang, J.-H. Zhao, and Y.-W. Dai, J. Phys.: Condens. Matter 22, 316005 (2010).

[38] P. Błoński and J. Hafner, J. Chem. Phys. 134, 154705 (2011).

[39] Y. Tang, Z. Yang, and X. Dai, J. Magn. Magn. Mater. 323, 2441 (2011).

[40] D. Xu, J. Zhao, and X. Wang, J. Nanopart. Res. 15, 1590 (2013).

[41] Y. Tang, Y. Tang, Z. Yang, Z. Yang, X. Dai, and X. Dai, J. Nanosci. Nanotechnol. 13, 1612 (2013).

[42] Q. Qi, H. Liu, W. Feng, H. Tian, H. Xu, and X. Huang, Comput. Mater. Sci. 96, 268 (2015).

[43] H. Shi, S. M. Auerbach, and A. Ramasubramaniam, J. Phys. Chem. C 120, 11899 (2016).

[44] C. R. C. Rêgo, P. Tereshchuk, L. N. Oliveira, and J. L. F. Da Silva, Phys. Rev. B 95, 235422 (2017).

[45] C. K. Acharya, D. I. Sullivan, and C. H. Turner, J. Phys. Chem. C 112, 13607 (2008).

[46] J. Wu, S. W. Ong, H. C. Kang, and E. S. Tok, J. Phys. Chem. C 114, 21252 (2010).

[47] G. Kim and S.-H. Jhi, ACS Nano 5, 805 (2011).

[48] D.-H. Lim and J. Wilcox, J. Phys. Chem. C 115, 22742 (2011).

[49] D. Xu, Y. Tian, J. Zhao, and X. Wang, J. Nanopart. Res. 17, 25 (2015).

[50] L. G. Verga, A. E. Russell, and C.-K. Skylaris, Phys. Chem. Chem. Phys. 20, 25918 (2018).

[51] Y. Tang, Z. Yang, and X. Dai, J. Nanopart. Res. 14, 844 (2012).

[52] I. Fampiou and A. Ramasubramaniam, J. Phys. Chem. C 117, 19927 (2013).

[53] G. Ramos-Sánchez and P. Balbuena, J. Electroanal. Chem. 716, 23 (2014).

[54] M. Mahmoodinia, P.-O. Åstrand, and D. Chen, J. Phys. Chem. C 121, 20802 (2017).

[55] M. Zhou, A. Zhang, Z. Dai, C. Zhang, and Y. P. Feng, J. Chem. Phys. 132, 194704 (2010).

[56] Y. Tang, Z. Yang, and X. Dai, Phys. Chem. Chem. Phys. 14, 16566 (2012).

[57] G. Kim, Y. Kawazoe, and K.-R. Lee, J. Phys. Chem. Lett. 3, 1989 (2012).

[58] Y. Tang, Z. Lu, W. Chen, W. Li, and X. Dai, Phys. Chem. Chem. Phys. 17, 11598 (2015).

[59] I. Fampiou and A. Ramasubramaniam, J. Phys. Chem. C 119, 8703 (2015).

[60] C. S. Wang, H. Wang, R. Wu, and R. Ragan, J. Phys. Chem. C 122, 21919 (2018).

[61] W. Qin and X. Li, J. Phys. Chem. C 114, 19009 (2010).

[62] R. J. Gasper and A. Ramasubramaniam, J. Phys. Chem. C 120, 17408 (2016).
[63] D.-H. Lim and J. Wilcox, J. Phys. Chem. C 116, 3653 (2012).

[64] Y. Tian, Y.-j. Liu, J.-x. Zhao, and Y.-h. Ding, RSC Adv. 5, 34070 (2015).

[65] H.-H. Liu, K.-L. Hsueh, and C.-W. Hong, Electrochim. Acta 259, 598 (2018).

[66] S. Back, J. Lim, N.-Y. Kim, Y.-H. Kim, and Y. Jung, Chem. Sci. 8, 1090 (2017).

[67] B. Hammer, O. Nilsen, and J. K. Nørskov, Catal. Lett. 46, 31 (1997).

[68] S. A. Wella, Y. Hamamoto, F. Iskandar, Suprijadi, Y. Morikawa, and I. Hamada, J. Chem. Phys. 152, 104707 (2020).

[69] N. Troullier and J. L. Martins, Phys. Rev. B 43, 1993 (1991).

[70] J. P. Perdew, K. Burke, and M. Ernzerhof, Phys. Rev. Lett. 77, 3865 (1996).

[71] M. Otani and O. Sugino, Phys. Rev. B 73, 115407 (2006).

[72] I. Hamada, M. Otani, O. Sugino, and Y. Morikawa, Phys. Rev. B 80, 165411 (2009).

[73] R. H. Telling, C. P. Ewels, A. A. El-Barbary, and M. I. Heggie, Nat. Mater. 2, 333 (2003).

[74] A. A. El-Barbary, R. H. Telling, C. P. Ewels, M. I. Heggie, and P. R. Briddon, Phys. Rev. B 68, 144107 (2003).

[75] S. Malola, H. Häkkinen, and P. Koskinen, Appl. Phys. Lett. 94, 043106 (2009).

[76] X. Q. Dai, J. H. Zhao, M. H. Xie, Y. N. Tang, Y. H. Li, and B. Zhao, Eur. Phys. J. B 80, 343 (2011).

[77] S. T. Skowron, I. V. Lebedeva, A. M. Popov, and E. Bichoutskaia, Chem. Soc. Rev. 44, 3143 (2015).

[78] G. Hennig, J. Appl. Phys. 36, 1482 (1965).

[79] R. Henson and W. Reynolds, Carbon 3, 277 (1965).

[80] Y. Ma, P. O. Lehtinen, A. S. Foster, and R. M. Nieminen, New J. Phys. 6, 68 (2004).

[81] C. Dong, W. Zhu, S. Zhao, P. Wang, H. Wang, and W. Yang, J. Appl. Mech. 80, 040904 (2013).

[82] E. Kano, A. Hashimoto, and M. Takeguchi, Appl. Phys. Express 10, 025104 (2017).

[83] B. Hammer and J. K. Nørskov, Nature (London) 376, 238 (1995).

[84] B. Hammer and J. K. Nørskov, Surf. Sci. 343, 211 (1995).

[85] B. Hammer, Y. Morikawa, and J. K. Nørskov, Phys. Rev. Lett. 76, 2141 (1996).

[86] R. McWeeny, J. Chem. Phys. 19, 1614 (1951).

[87] R. S. Mulliken, J. Chem. Phys. 23, 1833 (1955).

[88] R. S. Mulliken, J. Chem. Phys. 23, 1841 (1955).

[89] R. Hoffmann, Rev. Mod. Phys. 60, 601 (1988).

[90] H. Aizawa and S. Tsuneyuki, Surf. Sci. 399, L364 (1998).

[91] G. Blyholder, J. Phys. Chem. 68, 2772 (1964).

[92] R. S. Mulliken, J. Phys. Chem. 56, 295 (1952).

[93] M. Wolfsberg and L. Helmholz, J. Chem. Phys. 20, 837 (1952).

[94] See, e.g., W. Greiner, Quantum Mechanics: An Introduction, 4th ed. (Springer, New York, 2001). 